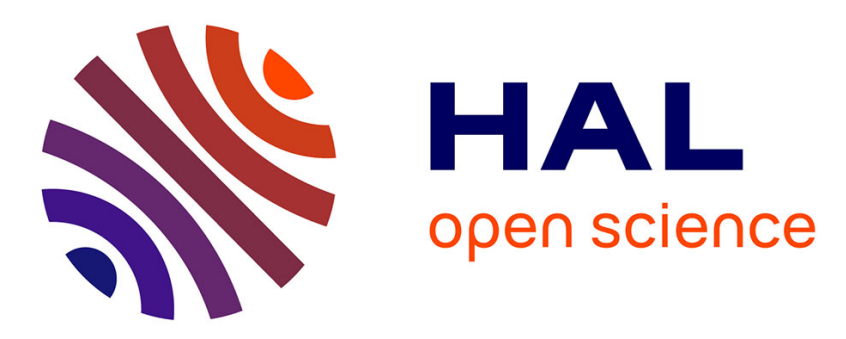

\title{
Synthesis of Biobased Polyols by Thiol-Ene Coupling from Vegetable Oils
}

Myriam Desroches, Sylvain Caillol, Vincent Lapinte, Rémi Auvergne, Bernard Boutevin

\section{- To cite this version: \\ Myriam Desroches, Sylvain Caillol, Vincent Lapinte, Rémi Auvergne, Bernard Boutevin. Synthesis of Biobased Polyols by Thiol-Ene Coupling from Vegetable Oils. International Journal of Biological Macromolecules, 2011, 44 (8), pp.2489. 10.1021/ma102884w . hal-00587652}

\section{HAL Id: hal-00587652 \\ https://hal.science/hal-00587652}

Submitted on 21 Apr 2011

HAL is a multi-disciplinary open access archive for the deposit and dissemination of scientific research documents, whether they are published or not. The documents may come from teaching and research institutions in France or abroad, or from public or private research centers.
L'archive ouverte pluridisciplinaire $\mathbf{H A L}$, est destinée au dépôt et à la diffusion de documents scientifiques de niveau recherche, publiés ou non, émanant des établissements d'enseignement et de recherche français ou étrangers, des laboratoires publics ou privés. 


\title{
Synthesis of Biobased Polyols by Thiol-Ene Coupling from Vegetable Oils
}

\author{
Myriam Desroches, Sylvain Caillol, Vincent Lapinte, Rémi Auvergne,* and Bernard Boutevin \\ Institut Charles Gerhardt Montpellier, UMR 5253 CNRS-UM2-ENSCM-UM1, Equipe I.A.M./S.OM 8, Rue de l'Ecole Normale, \\ 34296 Montpellier Cedex 5, France
}

Supporting Information

ABSTRACT: A model study of the radical addition of 2-mercaptoethanol onto oleic acid was performed under mild conditions (generation of radicals under UV light at room temperature without any photoinitiator). To evaluate the efficiency and the robustness of thiol-ene reaction, experimental parameters were varied, such as the irradiation intensity (ranging from 0.5 to $15.0 \mathrm{~W} / \mathrm{cm}^{2}$ ), the thiol/double bond ratio (ranging from $1.2 / 1$ to $5.0 / 1$ ), the solvent/double bond ratio (ranging from $0 / 1$ to $500 / 1$ ), and the number of double bonds per chain. It was especially shown that the higher the content of

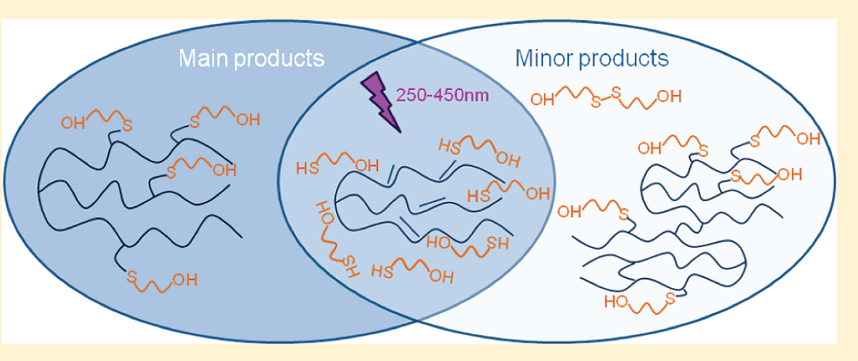
polyunsaturated fatty chains, the lower the rate of 2-mercaptoethanol grafting. Best yields were reached in $1 \mathrm{~h}$ reaction for a thiol/ene ratio of 3/1, without solvent, using maximum UV intensity. Side reactions, identified by NMR, FT-IR, LC-MS, and iodine titration, were upon esterification between the carboxylic acid function of oleic acid and the hydroxyl function of 2-mercaptoethanol, disulfide formation, double-bond isomerization, and inter- and intramolecular bond formation. Optimized conditions were then applied to vegetable oil functionalization. 2-Mercaptoethanol was photochemically grafted onto vinyl groups of rapeseed oil by thiol-ene addition to yield biobased polyols. Those polyols showed an average functionality of 3.6. The presence of byproducts was also confirmed; they were however found to exhibit hydroxyl functions and thus could be included in a polymer network. Finally, the functionalized rapeseed oil was used to synthesize polyurethanes with 1,6-hexamethylene diisocyanate and methylene diphenyl-4,4'diisocyanate. The thermal properties of elastomeric products were found to be similar to those from a commercial polyol (Desmophen 1150).

\section{INTRODUCTION}

In recent years, the sustainability is becoming increasingly important for the chemical industry; thus, the use of renewable resources has gained interest in polymer applications. Vegetable oils are extracted primarily from the seeds of oilseed plants. Their competitive cost, worldwide availability, and built-in functionality (ester functions and insaturations) make them attractive. The development of oleochemicals has been carried out from two distinct ways. The first one corresponds to the double-bond modification ${ }^{1}$ of crude oils or fatty acid derivatives. The second one is the carboxylic acid group modification of vegetable oils. ${ }^{2}$ The chemical functionalizations of unsaturated oils to produce polyols have been widely developed to prepare new polyurethane structures, which depend on triglyceride and isocyanate reagents used. ${ }^{3-5}$ These polyols are mainly obtained from intermediate epoxy oil either in one or two steps. The onestep reaction consists of the in-situ epoxidation followed by hydroxylation using acetic and sulfuric acids and hydrogen peroxide. ${ }^{6}$ The two-step reaction deals with the triglyceride epoxidation followed by the ring-opening of oxirane, based on the use of difunctional molecules such as alcohols ${ }^{7}$ or amines, ${ }^{8}$ obtaining polyols from vegetable oils. Moreover, vegetable oil double bonds were converted into primary alcohols through hydroformylation followed by hydrogenation. ${ }^{9}$ Eventually, ozonolysis was used to obtain polyols with terminal primary hydroxyl groups and different functionalities from natural vegetable oil and synthetic triglycerides. ${ }^{10}$ Those functionalization processes usually require at least two-step reaction and sometimes expensive catalysts.

Radical additions, such as thiol-ene coupling (TEC), are very attractive. A lot of unsaturated polymers were thus functionalized ${ }^{11-14}$ from thiol-ene addition. So far, TEC reactions have mainly been used both to polymerize and to cross-link fatty acids ${ }^{15-17}$ and triglycerides ${ }^{18}$ by using polyfunctional thiols. ${ }^{19}$ In addition, from TEC reaction, an effective optimization of vegetable oils lubricating property was performed either in one step or after grafting of mercaptosilanes on metallic surfaces. ${ }^{20}$ Recently, Meier et al. synthesized polyols by TEC from methyl 10-undecenoate and thiol alcohol without initiator. These polyols were used as polyester precursors. ${ }^{21}$

TEC reaction belongs to a set of reactions named "click" reactions ${ }^{22-24}$ characterized by high yields, simple reaction

\footnotetext{
Received: December 17, 2010

Revised: $\quad$ March 2, 2011

Published: March 30, 2011
} 
conditions, short reaction times, and high selectivity. Actually, thiol-ene addition reactions were extensively explored, and the "click chemistry" concept was often questioned. On the one hand, disulfide formation is a well-known secondary reaction. UV irradiation of a thiol function leads to cleavage of $\mathrm{S}-\mathrm{H}$ bond and creates radicals that could recombine into disulfide and dihydrogen. ${ }^{25}$ On the other hand, homopropagation represents another side reaction, which consumes double bonds, hence inducing nonquantitative modification. For instance, Schlaad et al. reported that such side reaction occurs during thiol-ene addition onto polybutadiene. ${ }^{13}$ Indeed, intramolecular formation of five- ${ }^{13,26}$ and six-membered ${ }^{13}$ cycles was clearly evidenced. We also reported the nonquantitative radical grafting of phosphonated thiols onto polybutadienes ${ }^{27}$ due to the presence of side reactions. More recently, Schlaad has found solution to cyclization reactions with the use of polyoxazolines. ${ }^{28}$ Schapman et al. also suspected some rearrangements during addition of a hindered thiosilane onto polybutadienes. ${ }^{29}$ Additionally, intermolecular propagation is also a possible secondary reaction pathway. Some studies showed chain extensions during alkenes functionalization. For example, Lotti reported SEC traces enlargements on functionalized polybutadienes with cysteine. ${ }^{30}$ These termination reactions were also observed during the functionalization of olefin/styrene copolymers. ${ }^{31,32}$ In the field of oleochemistry, Bantchev reported occurrence of solid grits, identified as oligomers, during addition of butanethiol onto vegetable oils. ${ }^{33}$

Finally, Bantchev also observed the formation of saturated fatty acids, which could arise from $\mathrm{H}^{\bullet}$ attack, instead of $\mathrm{RS}^{\bullet}$, on a double bond. This side reaction was also reported in case of double-bond isomerization with thiyl radical as catalyst. ${ }^{34}$ All these results prove how thiol-ene reaction is far from the "click chemistry" concept suggested by Sharpless. On vegetable oil derivatives, Meier functionalized methyl undecanoate and 10undecenol by several thiols such as mercaptoethanol, 1-thioglycerol, methyl thioglycolate, and 1,4-butanedithiol through thiol-ene thermocoupling. ${ }^{21}$ This thiol addition onto terminal double bond produced fewer byproduct than those achieved for the addition of these above mercaptans onto chain double bond. Meier did not report the byproducts formed and focused his study on the polycondensation of the monomer synthesized and the physical properties of the polyesters obtained.

To the author's knowledge, no study described the functionalization of raw vegetable oils by photochemical technology as well as the analyses of the obtained byproducts. Hence, the present work reports on the synthesis of oleochemical polyols with primary alcohol groups from unsaturated triglycerides involving thiol-ene coupling from Sharpless' concept. These oligo-polyols were used in polyurethane synthesis.

\section{EXPERIMENTAL SECTION}

Materials. Oleic acid (OA) was obtained from Croda and was used as supplied. Rapeseed oil (RO) was obtained from Novance and was used as supplied. Average composition of fatty compounds is given in Table S1 of the Supporting Information. 2-Mercaptoethanol (ME) (>98\%), dodecanethiol (>98\%), methyl oleate (MO) (99\%), methyl linoleate (ML) (>97\%), triolein (>99\%), methylene diphenyl-4,4'diisocyanate (MDI) (98\%), hexamethylene diisocyanate (HMDI) (99\%), ethyl acetate (99.5\%), ethanol (>99.8\%), methanol (>99.9\%), sulfuric acid $(96 \%)$, iodine $(1.000 \pm 0.001 \mathrm{~N}$ in water), potassium hydroxide (pellets, 99\%), and hydrochloric acid (1 M volumetric solution) were purchased from Sigma-Aldrich and used as received.
Desmophen 1150 (360 equiv wt) was supplied by Bayer and used as received. Deuterated solvent $\left(\mathrm{CDCl}_{3}\right)$ was purchased from Eurisotop (Saint-Aubin, France).

Analytical Techniques. All nuclear magnetic resonance $\left({ }^{1} \mathrm{H},{ }^{13} \mathrm{C}\right.$ NMR) measurements were recorded on a Bruker AC- $400 \mathrm{MHz}$ spectrometer at room temperature in deuterated chloroform. The chemical shifts were reported in parts per million relative to tetramethylsilane. A Nicolet Nexus 510P apparatus was utilized to real-time FT-IR spectroscopy of the thiol-ene addition with a resolution of $8 \mathrm{~cm}^{-1}$, using OMNIC software. The UV radiations were provided by a Novacure Effos apparatus (EFOS,Ontario, Canada) equipped with a $250-450 \mathrm{~nm}$ filter. The reactants were weighted and mixed in vials sheltered from light. A reaction mixture drop was put between two $\mathrm{KBr}$ windows, UV cell was placed in the spectrometer, IR analysis was started, and reaction mixture was exposed to UV after $1 \mathrm{~min}$. IR spectra were recorded every $10 \mathrm{~s}$. Double-bond consumption was monitored by a ratio based on peaks heights, more accurate than peak areas.

Size exclusion chromatography (SEC) was performed on a SpectraPhysics apparatus with one PLgel $5 \mathrm{~lm} 500$ Å column, one PLgel $5 \mathrm{~lm}$ $100 \AA$ A column (length: $300 \mathrm{~mm}$ ), and one PLgel $5 \mathrm{~lm}$ guard column (length: $50 \mathrm{~mm}$; internal diameter: $7.5 \mathrm{~mm}$ ). The detection was achieved with a SP8430 differential refractometer. The eluent used was tetrahydrofuran (THF) at a flow rate of $1 \mathrm{~mL} / \mathrm{min}$ at $35^{\circ} \mathrm{C}$. All determinations of molecular weight were performed relative to PMMA standards $\left(M_{\mathrm{p}} 161-770000 \mathrm{Da}\right)$.

Liquid chromatography-mass spectrometry (LC-MS) analyses were performed using an Alliance 2790 (Waters) HPLC, equipped with Hypersil C18 $3 \mu \mathrm{m}, 50 \times 2.1 \mathrm{~mm}$ (Thermo) column. The spectrometer is a Micromass Q-Tof (Waters) equipped with ESI source. The mass spectrum was recorded in positive mode between 50 and $1500 \mathrm{Da}$. Capillary tension and cone tension were 3000 and $20 \mathrm{~V}$, respectively. Flow rate: $0.2 \mathrm{~mL} / \mathrm{min}$; gradient: from $\mathrm{A} / \mathrm{B} 90 / 10$ at $t=0 \mathrm{~min}$ to $\mathrm{A} / \mathrm{B} 0 /$ 100 at $t=35 \mathrm{~min} ; \mathrm{A}: \mathrm{H}_{2} \mathrm{O}+0.1 \%$ TFA; B: acetonitrile $+0.1 \%$ TFA. Injection volume was $10 \mu \mathrm{L}$.

The volumetric titration of free thiol is based on a redox process, as follows:

$$
\begin{aligned}
2 \mathrm{RSH}+\mathrm{I}_{2} & \rightarrow \mathrm{RSSR}+2 \mathrm{HI} \\
\mathrm{I}_{2}+\mathrm{HI} & \rightarrow \mathrm{H}^{+}+{\mathrm{I}_{3}}^{-}
\end{aligned}
$$

The sample $(0.2 \mathrm{~g})$ was titrated by an iodine aqueous solution $(N=1$ $\mathrm{mol} \mathrm{L}{ }^{-1}$ ) under vigorous stirring until the color changes from colorless to pale yellow (showing the presence of $\mathrm{I}_{3}{ }^{-}$ions). Then, this titration allowed us to determine the free thiol concentration.

The acid number $\left(I_{\mathrm{a}}\right)$ refers to the potassium hydroxide weight (expressed in milligrams) required to neutralize the acid functions present in $1 \mathrm{~g}$ of sample. The sample $(0.2 \mathrm{~g})$ was dissolved in $5 \mathrm{~mL}$ of ethanol. The solution was then titrated by a solution of potassium hydroxide (0.1 M KOH solution). Phenolphthalein was used as the indicator. Each sample was titrated three times, and the acid value was calculated according to eq 1 :

$$
I_{\mathrm{a}}=\frac{V \times N \times 56.1}{m_{\mathrm{s}}}
$$

where $m_{s}, V$, and $N$ stand for the weight in grams of the sample, the volume in milliliters of the potassium hydroxide solution used for the titration, and the molar concentration of the potassium hydroxide solution used (in mol/L), respectively. For samples with low acid index, a $0.01 \mathrm{M}$ potassium hydroxide solution was chosen.

Thermogravimetry (TG) analyses were performed on a Q50 from TA Instruments. $20 \mathrm{mg}$ of sample in an aluminum pan was heated from room temperature to $500{ }^{\circ} \mathrm{C}$ under a nitrogen flow $(60 \mathrm{~mL} / \mathrm{min})$. The experiments were carried out at a heating rate of $20^{\circ} \mathrm{C} / \mathrm{min}$. 
Table 1. Reaction Conditions and Conversion for the Thiol Coupling to Fatty Alkenes ${ }^{a}$

\begin{tabular}{|c|c|c|c|c|c|c|c|c|}
\hline expt no. & fatty compound & thiol & thiol/double bond/ethanol molar ratio & $T\left({ }^{\circ} \mathrm{C}\right)$ & UV intensity $\left(\mathrm{W} / \mathrm{cm}^{2}\right)$ & $C_{\mathrm{dl}} 1 \mathrm{~h}^{b}(\%)$ & $C_{\mathrm{dl}} \mathrm{final}^{b}(\%)$ & $\operatorname{add~thiol~}^{c}(\%)$ \\
\hline 1a & $\mathrm{OA}$ & ME & $3 / 1 / 0$ & $\mathrm{Ti}$ & 15 & 99 & & 81 \\
\hline $1 b$ & $\mathrm{OA}$ & $\mathrm{ME}$ & $3 / 1 / 0$ & $\mathrm{Ti}$ & 15 & 100 & & 85 \\
\hline $1 c$ & $\mathrm{OA}$ & $\mathrm{ME}$ & $3 / 1 / 0$ & $\mathrm{Ti}$ & 15 & 98 & & 85 \\
\hline 2 & $\mathrm{OA}$ & $\mathrm{ME}$ & $3 / 1 / 0$ & $\mathrm{Ti}$ & 10 & 100 & & 85 \\
\hline 3 & $\mathrm{OA}$ & $\mathrm{ME}$ & $3 / 1 / 0$ & $\mathrm{Ti}$ & 5 & 90 & 100 & 85 \\
\hline 4 & $\mathrm{OA}$ & ME & $3 / 1 / 0$ & $\mathrm{Ti}$ & 2.5 & 85 & 100 & 87 \\
\hline 5 & $\mathrm{OA}$ & $\mathrm{ME}$ & $3 / 1 / 0$ & $\mathrm{Ti}$ & 0.5 & 40 & 97 & 85 \\
\hline 6 & $\mathrm{OA}$ & $\mathrm{ME}$ & $1.2 / 1 / 0$ & $\mathrm{Ti}$ & 15 & 55 & 92 & 73 \\
\hline 7 & $\mathrm{OA}$ & $\mathrm{ME}$ & $2 / 1 / 0$ & $\mathrm{Ti}$ & 15 & 95 & 100 & 85 \\
\hline 8 & $\mathrm{OA}$ & $\mathrm{ME}$ & $5 / 1 / 0$ & $\mathrm{Ti}$ & 15 & 100 & & 87 \\
\hline 9 & $\mathrm{OA}$ & $\mathrm{ME}$ & $3 / 1 / 2$ & $\mathrm{Ti}$ & 15 & 100 & & 81 \\
\hline 10 & $\mathrm{OA}$ & $\mathrm{ME}$ & $3 / 1 / 47$ & $\mathrm{Ti}$ & 15 & 83 & 91 & 59 \\
\hline 11 & $\mathrm{OA}$ & $\mathrm{ME}$ & $3 / 1 / 517$ & $\mathrm{Ti}$ & 15 & 45 & 100 & n.d. \\
\hline 12 & $\mathrm{OA}$ & $\mathrm{ME}$ & $3 / 1 / 0$ & 0 & 15 & 98 & & 81 \\
\hline 13 & $\mathrm{OA}$ & $\mathrm{ME}$ & $3 / 1 / 0$ & 30 & 15 & 100 & & 79 \\
\hline 14 & $\mathrm{OA}$ & DT & $3 / 1 / 0$ & $\mathrm{Ti}$ & 15 & 100 & & n.d. \\
\hline 15 & MO & $\mathrm{ME}$ & $3 / 1 / 0$ & $\mathrm{Ti}$ & 15 & 100 & & 99 \\
\hline 16 & $\mathrm{MO}$ & DT & $3 / 1 / 0$ & $\mathrm{Ti}$ & 15 & 100 & & n.d. \\
\hline 17 & ML & $\mathrm{ME}$ & $3 / 1 / 0$ & $\mathrm{Ti}$ & 15 & 30 & 96 & 50 \\
\hline 18 & ML & DT & $3 / 1 / 0$ & $\mathrm{Ti}$ & 15 & 100 & & n.d. \\
\hline 19 & $\mathrm{RO}$ & $\mathrm{ME}$ & $3 / 1 / 0$ & $\mathrm{Ti}$ & 15 & 35 & 98 & 63 \\
\hline 20 & $\mathrm{RO}$ & DT & $3 / 1 / 0$ & $\mathrm{Ti}$ & 15 & 32 & 98 & n.d. \\
\hline 21 & RO & & $3 / 0 / 0$ & $\mathrm{Ti}$ & 15 & 0 & 5 & \\
\hline 22 & triolein & $\mathrm{ME}$ & $3 / 1 / 0$ & $\mathrm{Ti}$ & 15 & 100 & & 100 \\
\hline
\end{tabular}

${ }^{a}$ ME: mercaptoethanol; DT: dodecanethiol; OA: oleic acid; MO: methyl oleate; ML: methyl linoleate; RO: rapeseed oil; Ti: from $20{ }^{\circ} \mathrm{C}$ at the beginning of photoreaction to $60{ }^{\circ} \mathrm{C}$ after $1 \mathrm{~h}$; n.d.: not determined. ${ }^{b}$ Double-bond conversion calculated from the integral of characteristic signals at 5.40 $\mathrm{ppm}$ assigned to unsaturations on ${ }^{1} \mathrm{H}$ NMR spectra. ${ }^{c}$ Thiol addition calculated from integral of $2.5 \mathrm{ppm}$ signal characteristic of proton in $\alpha$ position of thioether on ${ }^{1} \mathrm{H}$ NMR spectra.

Differential scanning calorimetry (DSC) analyses were carried out on a NETZSCH DSC200 calorimeter. Cell constant calibration was performed using indium, $n$-octadecane, and $n$-octane standards. Nitrogen was used as the purge gas. $10-15 \mathrm{mg}$ samples were sealed in hermetic aluminum pans. The thermal properties were analyzed at $20{ }^{\circ} \mathrm{C} /$ min between -100 and $+100{ }^{\circ} \mathrm{C}$ to observe the glass transition as well as crystallization/fusion processes. All the reported temperatures are onset values. For each sample, the thermal history was erased with a first heating ramp up to $100{ }^{\circ} \mathrm{C}$. From the DSC curve, glass transition temperature $T_{\mathrm{g}}$ was measured by the software.

Syntheses. Photochemical thiol/ene reaction was performed in quartz reactors of $20 \mathrm{~mL}$ equipped with an Ultracure 100SS plus/ Novacure lamp (unfiltered radiation between 250 and $450 \mathrm{~nm}$ ) and a magnetic stirrer under air. Reactants were introduced according to the amounts depicted in Table 1 . The total reaction mixture was $5 \mathrm{~g}$. Influences of solvent, thiol/double bond ratio, and UV intensity were studied. During reaction, the conversion of double bonds was monitored by ${ }^{1} \mathrm{H}$ NMR spectroscopy (vinyl proton signals at $5.40 \mathrm{ppm}$ ). The photochemical beam was stopped every hour to remove aliquots and to measure the temperature in the reactor. With fatty acids, reaction mixture was homogeneous at the beginning of the reaction. With vegetable oil, two phases were observed at the beginning of the reaction, and then homogenization increased with double-bond conversion.

After reaction, the viscous liquid was dissolved in ethyl acetate $(20 \mathrm{~mL})$ and extracted with water $(3 \times 20 \mathrm{~mL})$ to eliminate the excess of 2-mercaptoethanol. The organic layer was dried over anhydrous magnesium sulfate and filtered. A pale yellow viscous liquid was recovered after evaporation of the solvent under reduced pressure $\left(3 \cdot 10^{-2} \mathrm{mbar}, 30^{\circ} \mathrm{C}\right)$.
For some experiments, 2-mercaptoethanol was directly removed by distillation under reduced pressure $\left(3 \times 10^{-2} \mathrm{mbar}, 60^{\circ} \mathrm{C}\right)$.

For some experiments (nos. 12 and 13), reactions were carried out in a $100 \mathrm{~mL}$ round-bottom flask equipped with a magnetic stirrer, and temperature is kept at 0 and $30^{\circ} \mathrm{C}$, respectively, with cooled bath. After reactants introduction, UV source was introduced in the round-bottom flask through a septum.

Polyurethane Synthesis. Polyurethanes were prepared from the synthesized oleochemical polyol or Desmophen 1150, which reacted with either methylene diphenyl-4,4'-diisocyanate (MDI) or 1,6-hexamethylene diisocyanate (HDI). The $\mathrm{OH} / \mathrm{NCO}$ ratio was 1.00/1.05. Suitable amounts of polyol and diisocyanate were weighed in a glass container, mixed vigorously, poured in a metallic mold, and placed in a vacuum oven at $20^{\circ} \mathrm{C}$ for $10 \mathrm{~min}$ to degas the $\mathrm{CO}_{2}$ released during the side reaction of isocyanate with moisture or carboxylic acids and the air trapped during mixing. Air was then introduced to the oven, and the samples were cured at $65^{\circ} \mathrm{C}$ for $24 \mathrm{~h}$.

\section{RESULTS AND DISCUSSION}

This work is divided into two parts: the first one is a model study of the radical addition of 2-mercaptoethanol (ME) onto oleic acid while the second one corresponds to the polyol synthesis from thiol-ene reaction onto vegetable oil.

First, photoaddition of ME onto double bonds of oleic acid and methyl oleate was studied (Scheme 1a,b). The byproducts were identified, and the reaction conditions were optimized. Then, polyols were synthesized from rapeseed oil and characterized by means of NMR spectroscopy, size exclusion chromatography, 
Scheme 1. 2-Mercaptoethanol Photoaddition onto Fatty Compounds Bearing One Double Bond per Chain

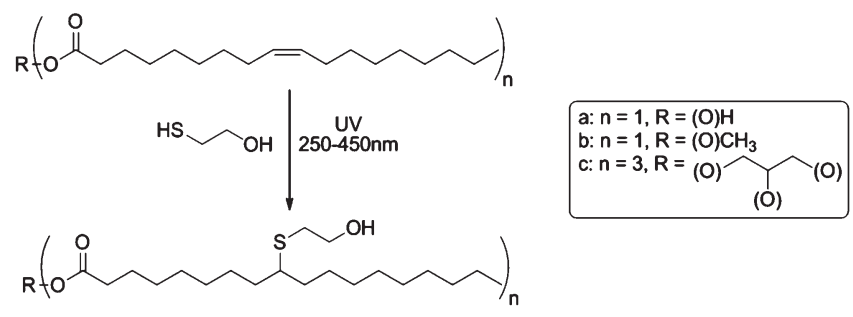

and mass spectroscopy. Table 1 gathers all the experiments carried out in this study.

Model Study of Thiol/Ene Reaction onto Oleic Acid. The radical addition of $\mathrm{ME}$ onto oleic acid (OA) was carried out under air, with a thiol/ene stoichiometric ratio ranging from 1.2/1 to 5.0/ 1 , under UV irradiation $(250-450 \mathrm{~nm})$ for $1-6 \mathrm{~h}$ (Scheme $1 \mathrm{a})$.

The product obtained from experiments 1a to $1 \mathrm{c}$ (Table 1 ) was purified by liquid-liquid extraction and analyzed from different techniques to assess the thiol-ene coupling and to identify the byproducts.

Figure 1 exhibits the ${ }^{1} \mathrm{H}$ NMR spectra of pristine OA (Figure 1a) and of reaction mixture after $1 \mathrm{~min}$ (Figure $1 \mathrm{~b}$ ) and after $1 \mathrm{~h}$ (Figure 1c). The ${ }^{1} \mathrm{H}$ NMR spectrum of the final product after liquid-liquid extraction is also supplied (Figure 1d). The disappearance of both signals centered at $5.32 \mathrm{ppm}(\mathrm{CH}=\mathrm{CH})$ and at $2.00 \mathrm{ppm}\left(\mathrm{CH}_{2}-\mathrm{CH}=\right)$ of the final product (Figure 1d) proved a quantitative conversion of the double bond. Simultaneously, the occurrence of the characteristic signal corresponding to the thioether product, i.e., the multiplet $\mathrm{m}$ at $2.5 \mathrm{ppm}\left(\mathrm{CH}_{2}-\mathrm{S}\right)$, tended to demonstrate the $\mathrm{ME}$ addition. The intensity of proton signals $\mathrm{k}$ and $\mathrm{l}$ from 2-mercaptoethanol, centered at 2.7 and $3.7 \mathrm{ppm}$, respectively, allowed evaluating the addition of $0.85 \mathrm{ME}$ unit per oleic acid molecule. However, 1 unit per OA was expected, accordingly to quantitative double bond conversion. As demonstrated below, this difference was related to side reactions, leading to inter- or intramolecular bonds. Two triplets at 2.9 and $3.9 \mathrm{ppm}$ were noted from spectra of nonpurified products (Figure 1c). They corresponded to disulfide obtained by recombination of two thiyl radicals.

Both iodine titration ${ }^{35}$ and ${ }^{1} \mathrm{H}$ NMR techniques allowed determining the thiol conversion into disulfide. Then, mol \% of disulfide can be calculated from eq 2 .

$$
\% \text { disulfide }=\left(1-\frac{C_{\text {thiol }}}{C_{\text {thiol }}^{\text {theo }}}\right) \times 100
$$

where $C_{\text {thiol }}$ and $C_{\text {thiol }}^{\text {theo }}$ correspond to the titrated and theoretical concentrations of free thiols (in $\mathrm{mmol} / \mathrm{g}$ ), respectively.

From ${ }^{1} \mathrm{H}$ NMR spectra, the mol \% of disulfide can be calculated from eq 3 .

$$
\% \text { disulfide }=\frac{\frac{I_{\mathrm{CH}_{2} \mathrm{SS}}}{2}}{I_{\mathrm{CH}_{2} \mathrm{SH}}+\frac{I_{\mathrm{CH}_{2} \mathrm{SS}}}{2}} \times 100
$$

where $I_{\mathrm{CH}_{2} \mathrm{SS}}$ and $I_{\mathrm{CH}_{2} \mathrm{SH}}$ correspond to the integrals of the signal assigned to protons in $\alpha$ position of disulfide (at $3.9 \mathrm{ppm}$ ) and in $\alpha$ position of free thiol (at $3.7 \mathrm{ppm}$ ), respectively.

Both ${ }^{1} \mathrm{H}$ NMR and titration from experiments $1 \mathrm{a}, 1 \mathrm{~b}, 1 \mathrm{c}$ led to determine the content of disulfide ranging from 1 to $2 \mathrm{~mol} \%$. Further purification was not required to decrease the low disulfide content since this diol would be able to be used in polyol chemistry. Disulfide could be however removed from liquid-liquid extraction, owing to its water miscibility. Three washings were required to completely remove disulfide, which decrease the final yield. Indeed, the excess of ME must be removed to avoid terminal reaction due to monofunctional alcohol. ME can be easily extracted from vacuum distillation unlike disulfide ( $\mathrm{bp}=160^{\circ} \mathrm{C}$ at $\left.4.7 \mathrm{mbar}\right)$. Combination of two techniques allowed obtaining well-purified fatty products, since free thiols, introduced in excess, were detected after purification at only $0.1 \mathrm{mmol} / \mathrm{g}$; thus, no disulfide products were observed from ${ }^{1} \mathrm{H}$ NMR analysis after treatment. Figure $1 \mathrm{~d}$ also exhibited a signal, centered at $4.2 \mathrm{ppm}$, characterizing methylene protons in $\alpha$ position of esters groups, being obtained from the esterification between oleic acid and the alcohol function of ME. The signal assigned to oleic acid vinyl protons, centered at 5.33 ppm (multiplet named $\mathrm{X}$ in Figure 1a), underwent to slight low field shift to $5.37 \mathrm{ppm}$ (multiplet named $\mathrm{X}^{\prime}$ in Figure $1 \mathrm{~b}$ ) after thiol addition. This shift was attributed to a transition of cis double bond $(\mathrm{X})$ to trans one $\left(\mathrm{X}^{\prime}\right)$. The double-bond isomerization mechanism during TEC has been extensively studied and is known to occur fastly. ${ }^{36}$ The competing cis-trans equilibrium appears to affect the rate of the final product formation. In a recent work, Claudino et al. concluded from FT-IR, Raman, and NMR spectroscopy that the grafted product was mainly formed from the trans isomer. ${ }^{37}$ In our case, the intensity of X decreased rapidly whereas the one of $\mathrm{X}^{\prime}$ increased and then decreased slowly until complete disappearance, which tends to confirm the described dominant route. The isomerization mechanism could also be evidenced from online FT-IR analysis of the reaction.

To avoid large vibration band at $3400 \mathrm{~cm}^{-1}$ assigned to $-\mathrm{OH}$ bonds of oleic acid and ME, which may overlap double bond vibration band at $3008 \mathrm{~cm}^{-1}$ in FT-IR analysis, the reaction was performed between dodecanethiol and methyl oleate (experiment 16). Dodecanethiol exhibited the same reactivity as ME onto oleic double bond (confirmed from ${ }^{1} \mathrm{H}$ NMR analysis). The doublebond conversion was monitored from FT-IR by the decrease of both the vibration band at $3008 \mathrm{~cm}^{-1}$ (stretching $\mathrm{CH} \mathrm{sp}^{2}$ ) and that at $721 \mathrm{~cm}^{-1}$ (cis CC deformation). The isomerization mechanism during thiol-ene reaction ${ }^{18,33}$ was characterized by the evolution of the $\mathrm{C}=\mathrm{C}$ bond vibration band at $964 \mathrm{~cm}^{-1}$ (Figure 2).

Cis configuration of fatty acid double bonds was converted into trans configuration because of the reversibility of thiyl radical addition onto olefins (Scheme 2). In thiol-ene reaction, addition of $\mathrm{RS}^{\bullet}$ radical was monitored by radical abstraction of a hydrogen atom from another thiol. This last step is the limitative step of the reaction ${ }^{38}$ and depends on thiol structure.

Neither the formation of $\mathrm{CH}-\mathrm{S}$ bond nor the vanishing of $\mathrm{S}-\mathrm{H}$ bond could be characterized from FT-IR spectroscopy because the intensities of their corresponding vibration bands at $600-700$ and $2500-2600 \mathrm{~cm}^{-1}$ remained too weak. ${ }^{39}$

The OA double bond conversion was also confirmed by the absence of $=\mathrm{CH}$ signal (centered at $131.5 \mathrm{ppm}$ ) from the ${ }^{13} \mathrm{C}$ NMR spectrum of the final product (Figure $3 a, b$ ). The appearance of a signal at $46 \mathrm{ppm}$ corresponding to asymmetric carbon in $\alpha$ position of thioether $(\mathrm{CH}-\mathrm{S})$ confirmed thiol addition. Interestingly, the carbonyl area was characterized by two signals at 174 and $180 \mathrm{ppm}$, whereas the initial spectrum of OA only showed one signal at $180 \mathrm{ppm}$. This second signal may be explained from two possible side reactions (Scheme 3).

The first side reaction is the thio-esterification. Indeed, syntheses of mercapto-esters were previously achieved from triglycerides. ${ }^{40}$ However, formation of thioesters required a $10 \mathrm{~h}$ reaction at high 


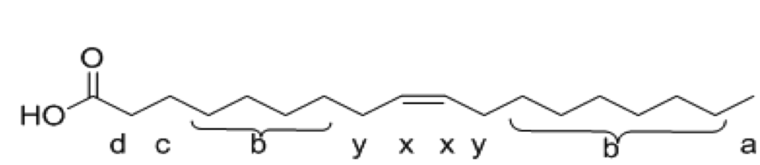

(a)<smiles>CC1CC1</smiles>
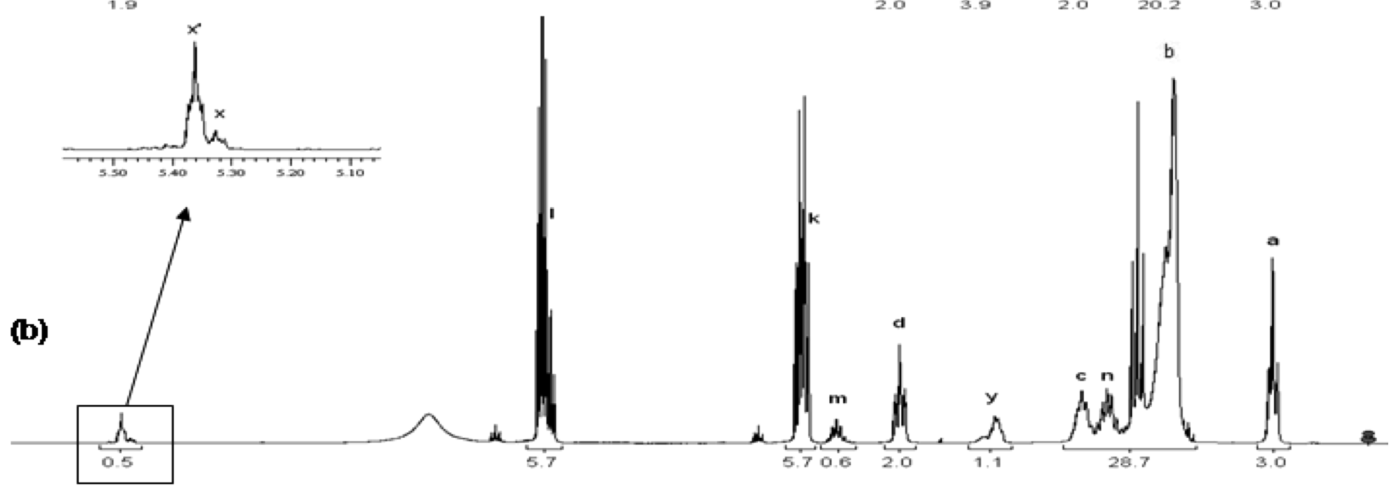

(c)
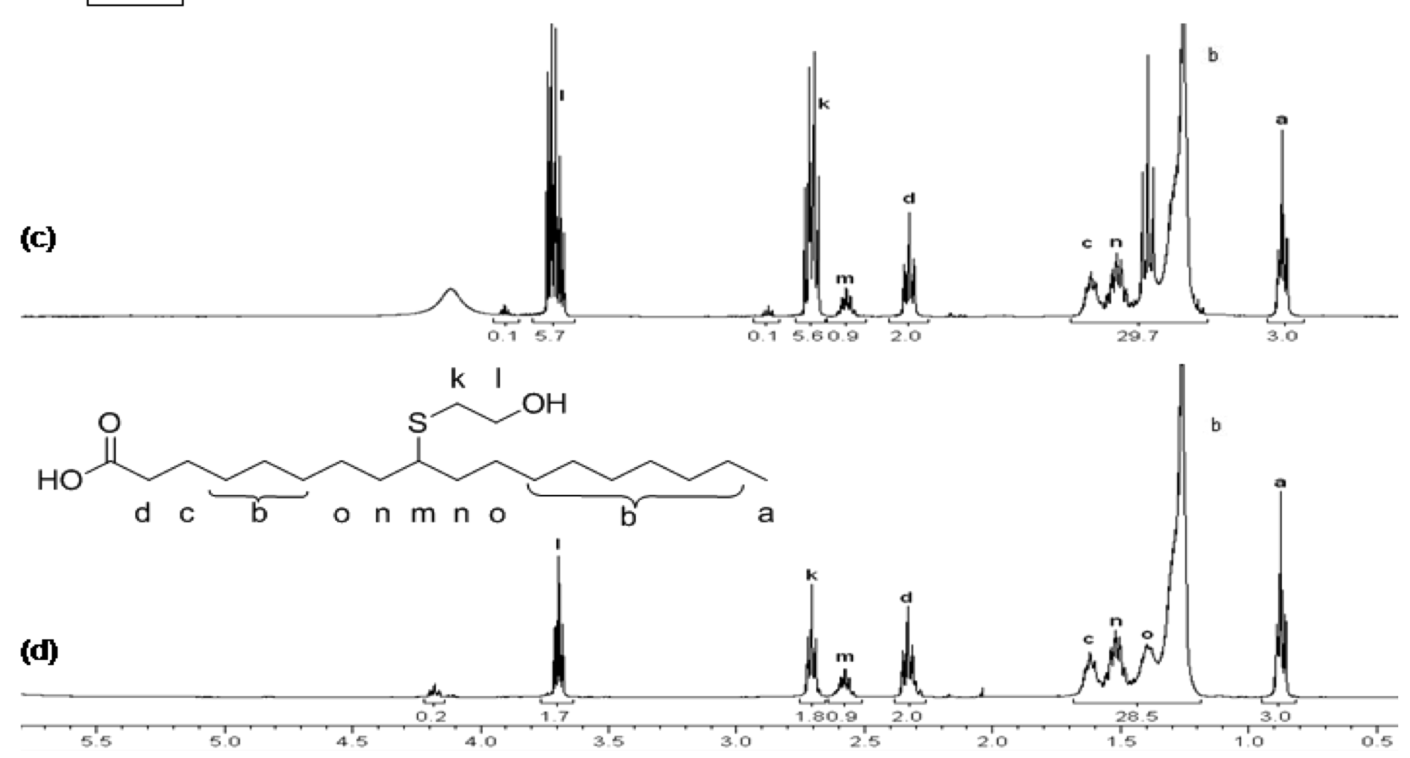

Figure 1. ${ }^{1} \mathrm{H}$ NMR spectra $\left(\mathrm{CDCl}_{3}\right)$ of oleic acid (a), reaction mixture of mercaptoethanol addition on oleic acid $\left(\right.$ ratio $\left.3 / 1, I=15 \mathrm{~W} / \mathrm{cm}^{2}\right)$ at $t_{\text {irradiation }}$ $=1 \mathrm{~min}(\mathrm{~b})$, at $t_{\text {irradiation }}=1 \mathrm{~h}(\mathrm{c})$, and product after purification $(\mathrm{d})$.

temperature $\left(140{ }^{\circ} \mathrm{C}\right)$ under acid or basic catalysis, ${ }^{40}$ whereas mild conditions were used in the present study. Besides, thioester signal, expected at $200 \mathrm{ppm}$, was not observed from the ${ }^{13} \mathrm{C}$ NMR spectrum. The second side reaction is the esterification reaction between the alcohol group of 2-mercaptoethanol and the acid group of oleic acid, the signal at $174 \mathrm{ppm}$ corresponding to the carbonyl ester function. This conclusion was confirmed by the presence of a triplet at $4.2 \mathrm{ppm}$ from the ${ }^{1} \mathrm{H}$ NMR spectrum (Figure 1d), which corresponded to the methylene ester function (the methylene thioester function triplet would be expected at 3 ppm).

According to ${ }^{1} \mathrm{H}$ NMR spectroscopy, the ester molar content, calculated from eq 4, was about $6 \mathrm{~mol} \%$ in the reaction conditions of experiments $1 \mathrm{a}, 1 \mathrm{~b}$, and $1 \mathrm{c}$.

$$
\% \text { ester }=\frac{I_{\mathrm{CH}_{2} \mathrm{OCO}}}{I_{\mathrm{CH}_{2} \mathrm{COO}}} \times 100
$$

where $I_{\mathrm{CH}_{2} \mathrm{OCO}}$ and $I_{\mathrm{CH}_{2} \mathrm{COO}}$ correspond to the integrals of the methylene ester function at $4.2 \mathrm{ppm}$ and those adjacent to the carbonyl at $2.3 \mathrm{ppm}$, respectively. Esterification was also confirmed by acid titration, since $195 \mathrm{mg} \mathrm{KOH} / \mathrm{g}$ was obtained for $\mathrm{OA}$ and only $145 \mathrm{mg} \mathrm{KOH} / \mathrm{g}$ for modified OA.

The ester molar content, calculated from eq 5 , was $5 \mathrm{~mol} \%$, i. e., in agreement with that determined from ${ }^{1} \mathrm{H}$ NMR spectroscopy.

$$
\% \text { ester }=\left(1-\frac{I_{\mathrm{a}}^{\mathrm{final}} M^{\mathrm{final}}}{I_{\mathrm{a}}^{\mathrm{OA}} M^{\mathrm{OA}}}\right) \times 100
$$

where $I_{\mathrm{a}}^{\mathrm{OA}}, M^{\mathrm{OA}}, I_{\mathrm{a}}^{\mathrm{final}}$, and $M^{\mathrm{final}}$ correspond to the acid number of oleic acid, the molecular weight of oleic acid, the acid number of functionalized oleic acid, and the molecular weight of oleic acid functionalized, respectively. 
This esterification side reaction involved the formation of fatty thiols (molecule VI, Figure 4) which were not removed from described purification techniques.

Oleic acid LC-MS analysis (Table 2 and Figure S1 from Supporting Information) exhibits both expected stereoisomers of the thioether at 20.08 and $20.33 \mathrm{~min}$, with a grafting onto

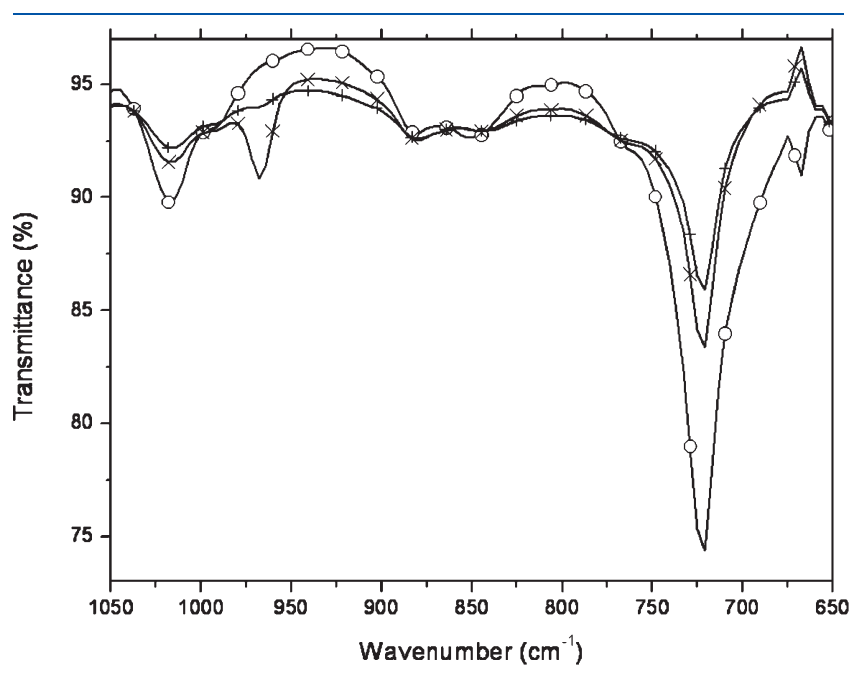

Figure 2. Infrared spectra for the photoreaction of a $3 / 1$ dodecanethiol/methyl oleate mixture: infrared spectrum after $0(O), 5(\times)$, and $60 \mathrm{~min}(+)$ of reaction. A UV irradiance of $15 \mathrm{~W} / \mathrm{cm}^{2}$ was used. 9th and 10th carbon atoms (molecules Ia and Ib, Figure 4). Linoleic acid, having two grafted ME unit, can also be identified at $16.4 \mathrm{~min}$ (molecules II, Figure 4) as well as C20 fatty acid, having one ME group, at 24.10 min (molecule III, Figure 4).

The intramolecular cyclization of fatty acids is known to occur at high temperature. This reaction was particularly studied for food processing, ${ }^{41,42}$ and the formation of mono- and dicycles (saturated or not) was described. However, unmodified oleic acid, or intramolecular cyclization product, were not detected by LC-MS analyses. The $283.3 \mathrm{~g} / \mathrm{mol}$ molecule exhibited indeed the same LC trace that the one at $343.3 \mathrm{~g} / \mathrm{mol}$, implying that the first one can be attributed to a degradation of the main molecule during the mass analysis.

This model study showed that thiol-ene addition onto OA led to expected hydroxy fatty acids (molecules Ia, Ib, II, and III, Figure 4) but also to five different side products.

Scheme 2. Schematic Illustration of the Cis-Trans Isomerization during the Thiol-Ene Free-Radical Addition onto Internal Double Bond

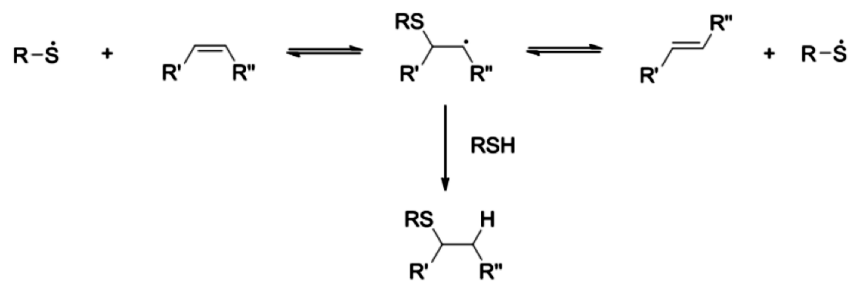

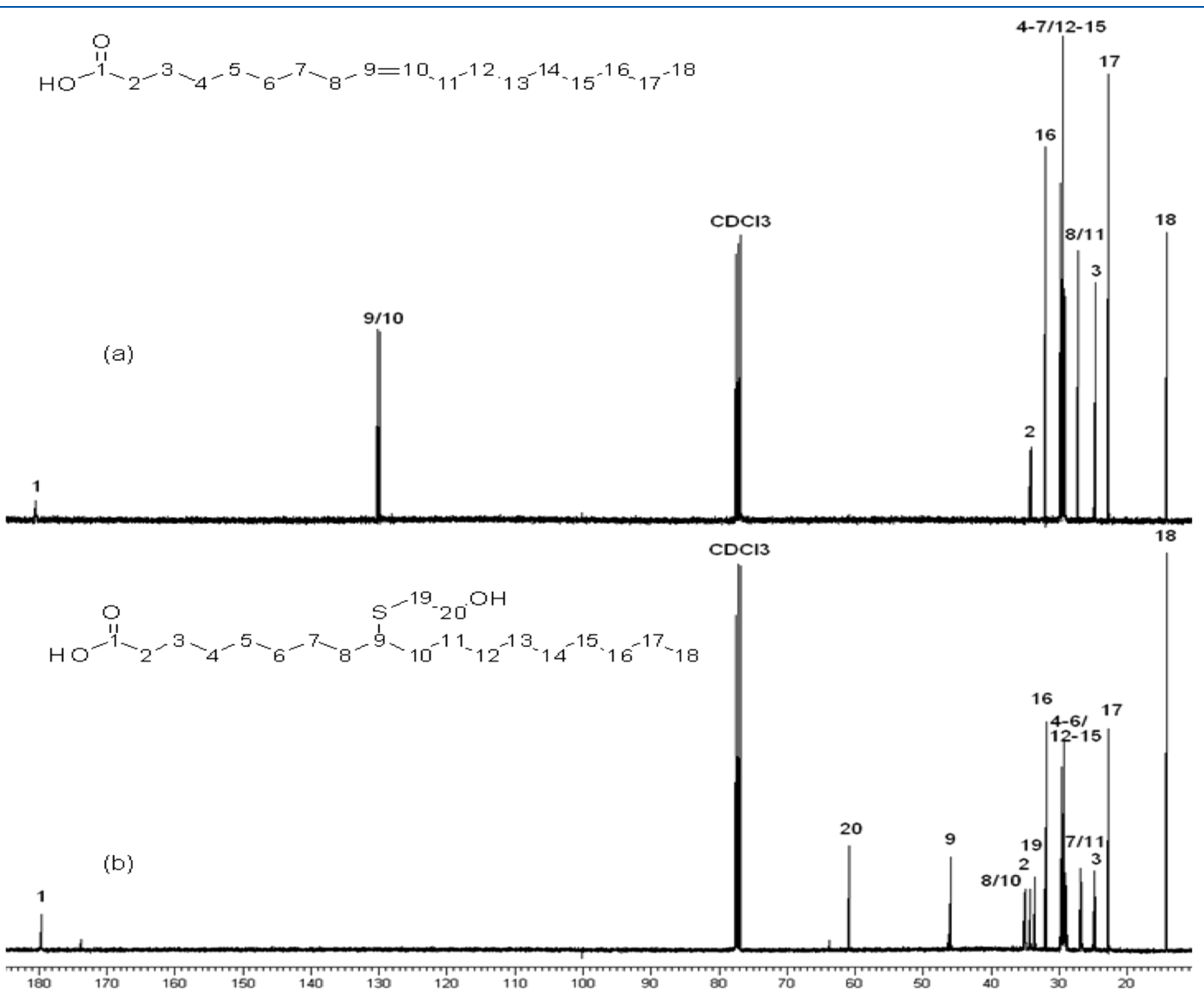

Figure 3. ${ }^{13} \mathrm{C} \mathrm{NMR}$ spectra $\left(\mathrm{CDCl}_{3}\right)$ of oleic acid (a) and its product after the thiol-ene coupling with 2-mercaptoethanol (b) (ratio thiol/ene 3/1, irradiated $1 \mathrm{~h}$ at $\left.15 \mathrm{~W} / \mathrm{cm}^{2}\right)$. 
Some side products might not be clearly identified from the mass spectrum. Indeed, a byproduct detected at $32.93 \mathrm{~min}$ from LC trace exhibited a molecular weight of $343.3 \mathrm{~g} / \mathrm{mol}$. Both esterification products (molecules V and VI, Figure 4) of free ME on oleic acid exhibited the same molecular weight. It was worth noting that dimerization can be achieved by transesterification between two oleic acid-functionalized molecules (molecule VII, Figure 4). This byproduct was detected at $32.81 \mathrm{~min}$ from LC MS analysis.

Moreover, in the above-described experiment conditions (under air), oxidation reactions were expected. In their review,

Scheme 3. Suggested Side Reactions from Oleic Acid Carboxylic Acid Group

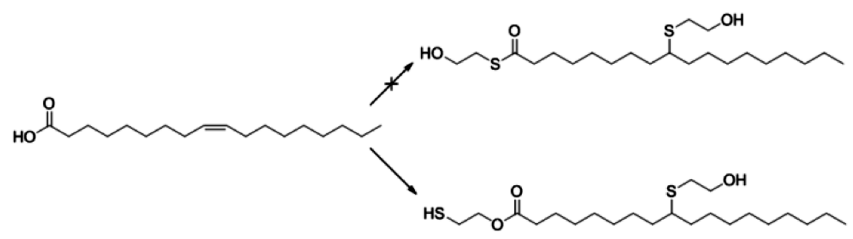

Hoyle et al. highlighted the insensitivity of TEC to oxygen inhibition. ${ }^{43}$ The carbon-centered radical formed by thiyl addition onto a double bond can combine with $\mathrm{O}_{2}$. The peroxy radicals formed by oxygen scavenging can abstract a thiol hydrogen, thus allowing the formation of a thiyl radical which allow the reaction to proceed. The thus formed hydroperoxides can be converted, among other things, into arylthio alcohols ${ }^{44}$ (Scheme 4). However, in our case, neither LC MS analyses nor NMR analyses allowed pointing out secondary hydroxyl group formation.

Dimers could also be generated from oxygen bonds. Some works based on mass spectroscopy analyses showed that crosslinking bonds of fatty unsaturated chains in alkyd paints were mostly COC or COOC bonds. ${ }^{45}$ Oligomerization byproduct were evidenced from LC MS analysis. After $33 \mathrm{~min}$, higher molecular weight molecules were detected. The LC MS conditions did not allow to separate higher molecular weight molecules, and identification of those byproducts was not successful.

Experimental parameters were systematically varied to find out optimum conditions for quantitative functionalization of double bonds.

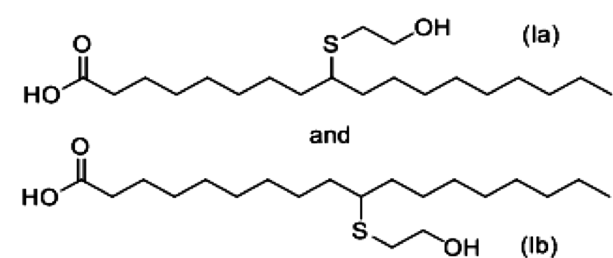<smiles>CCCCCCCC(CCO)SCCO</smiles><smiles>CCCCCCCCCCC(CCCCCCCCC(=O)O)SCCO</smiles>

(lb)

(III)
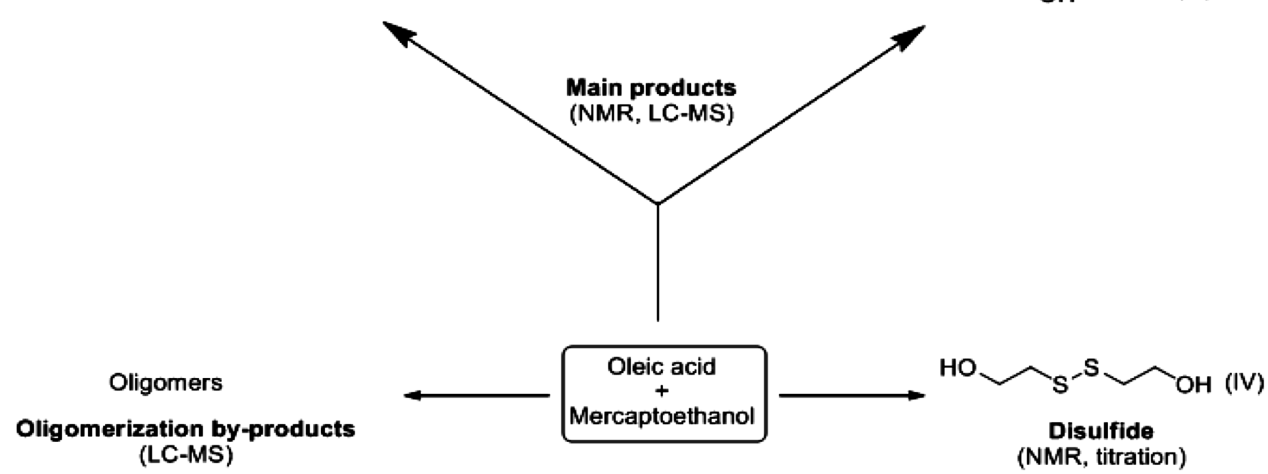

Disulfide

(NMR, titration)

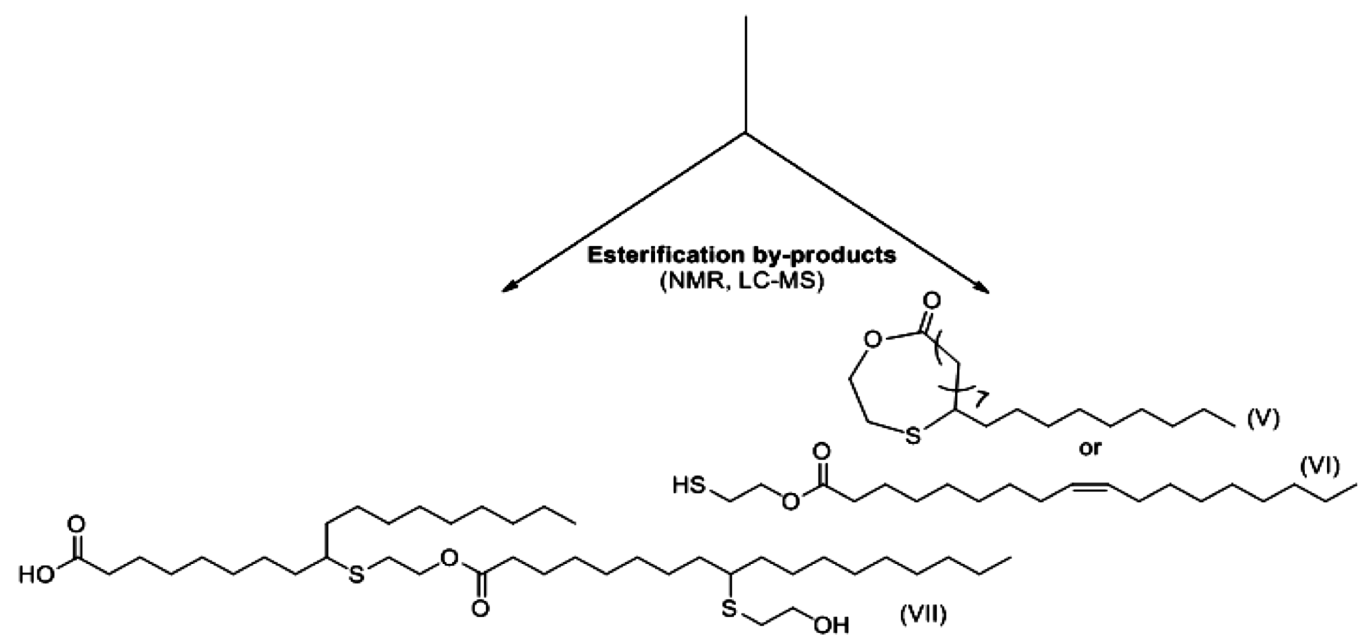

Figure 4. Expected products and byproducts obtained by thiol-ene photoaddition of mercaptoethanol onto oleic acid and their identification techniques. 
Table 2. LC-MS Data for 2-Mercaptoethanol Grafted onto Oleic Acid, Methyl Oleate, and Methyl Linoleate Obtained from Irradiation of a Thiol/Ene Mixture of 3/1, at $15 \mathrm{~W} / \mathrm{cm}^{2}$

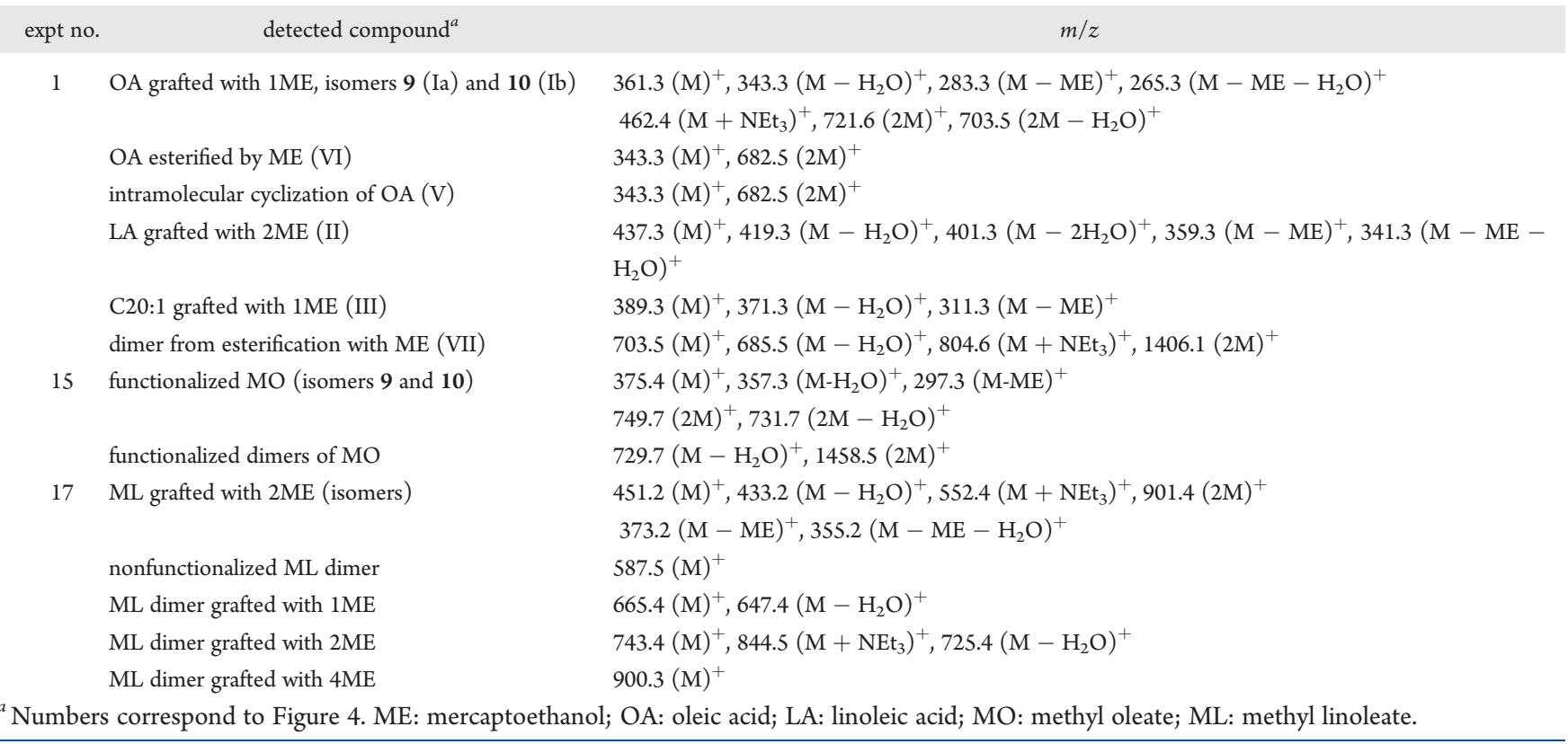

Scheme 4. Oxidation Mechanism for Thiol Addition onto Olefins

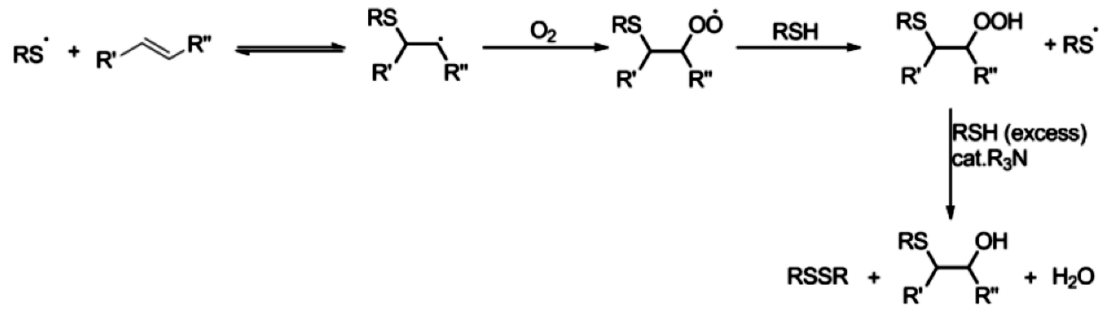

Variation of Synthesis Parameters. The effect of UV intensity onto double-bond conversion was carried out through experiments $1-5$ (Table 1). ${ }^{1} \mathrm{H}$ NMR analyses clearly illustrated that UV intensity was not a main parameter for the addition reaction, as the grafted thiol amount was evaluated at $85 \%$. Further, the disulfide amount remained unchanged, i.e., about $1.5 \% \mathrm{~mol}$. An increase of UV intensity from 0.5 to $15.0 \mathrm{~W} / \mathrm{cm}^{2}$ led to an increase of the reaction rate. At $350 \mathrm{~min}$, the final conversion remained unchanged whatever the UV intensity (Figure $\mathrm{S} 2$ from the Supporting Information). The amount of produced ester increased to $10 \mathrm{~mol} \%$ at low UV intensity (experiments 4 and 5). This could be explained by a longer time at "high temperature" due to longer irradiation time. Interestingly, a UV intensity of 15 $\mathrm{W} / \mathrm{cm}^{2}$ allowed both to increase the kinetic of addition reaction and to produce a lower amount of byproduct.

Thiol content was an important parameter (experiments 1, 6, 7, and 8 , Table 1) since it influenced both the reaction time and the double-bond conversion (Figure 5). For thiol-ene molar ratios of $2 / 1,3 / 1$, and $5 / 1$, the double-bond conversion was $100 \mathrm{~mol} \%$, whereas for molar ratio of $1.2 / 1$, only $73 \mathrm{~mol} \%$ of double bonds were reacted. In addition, the reaction was very slow.

The thiol/ene molar ratio also influenced esterification side reaction, as shown from ${ }^{1} \mathrm{H} \mathrm{NMR}$ spectroscopy. Indeed, $25 \mathrm{~mol}$ $\%$ of esters were formed for a thiol/ene ratio of $1.2 / 1$, whereas no

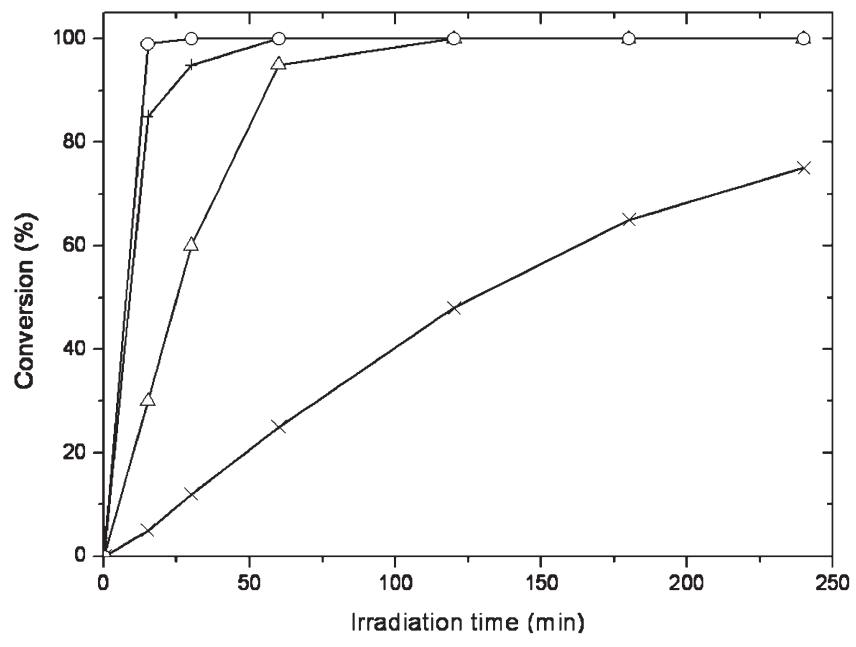

Figure 5. Double-bond conversion during the photoaddition reaction of 2-mercaptoethanol onto oleic acid irradiated at $15 \mathrm{~W} / \mathrm{cm}^{2}$ at different thiol/ene ratio: $1.2 / 1(\times), 2.0 / 1(\Delta), 3.0 / 1(+)$, and 5.0/1 $(O)$.

signal were observed for 5.0/1 ratio. Finally, thiol/ene ratio was a major parameter for the double-bond conversion, the reaction rate, and the byproduct formation. The best results were 
obtained for a ratio of 5.0/1. Nevertheless, to avoid the purification of high ME excess, a 3/1 ratio was preferred.

Vegetable oils and their derivatives have different viscosities. To check the viscosity influence, a solvent was used to decrease viscosity, and reaction times were compared to those obtained from bulk reactions (experiments 9-11, Table 1). Ethanol was chosen as the solvent since it could be produced from natural resources and is highly transparent to UV irradiation between 250 and $450 \mathrm{~nm}$ (a blank made by irradiating oleic acid and ethanol for $1 \mathrm{~h}$ indicates that no esterification reaction occurred). The dilution induced a decrease of reaction rate (Figure S3 from the Supporting Information). NMR analyses of obtained products (experiment 11) allowed determining the amount of disulfides at about $1 \mathrm{~mol} \%$ at complete conversion of double bonds. The ester molar content slightly increased with dilution since $10 \mathrm{~mol} \%$ of ester byproduct were detected from experiment 10. Therefore, bulk reaction appeared to be beneficial both for decreasing the reaction time and for limiting side reactions.

Reaction media underwent an increase of the temperature during irradiation $\left(60^{\circ} \mathrm{C}\right.$ after $\left.1 \mathrm{~h}\right)$. No clear difference of reaction rate was observed at 0 and $30^{\circ} \mathrm{C}$ (experiments 12 and 13 , Table 1 ). A slight increase of grafted thiols at $0{ }^{\circ} \mathrm{C}$ could yet prove that addition reaction was favored at lower temperature. Interestingly, no ester peak (at $4.17 \mathrm{ppm}$ ) was observed from ${ }^{1} \mathrm{H}$ NMR spectra. Thus, for lower temperature, esterification reaction between $\mathrm{ME}$ and $\mathrm{OA}$ was reduced. Moreover, disulfides represented around $2.5 \mathrm{~mol} \%$ of introduced thiols. In conclusion, the temperature regulation did not improve the reaction significantly.

Influence of Fatty Compound. The influence of acid group of fatty compounds on thiol-ene reaction has also been investigated. ME addition was thus carried out onto methyl oleate and methyl linoleate (experiments 15 and 17). Noteworthy, the protons characterizing the transesterification were not detected from ${ }^{1} \mathrm{H}$ NMR analyses of functionalized methyl esters. In the presence of methyl esters, disulfide did not exceed $0.3 \%$, suggesting that acidity may influence the formation of this byproduct.

As far as the number of double bonds per chain was concerned, thiol-ene coupling of methyl oleate (Scheme $1 \mathrm{~b}$ ) was found to proceed faster and with a higher efficiency, in comparison to its methyl linoleate counterpart. Indeed, $5 \mathrm{~h}$ was required to reach complete conversion of methyl linoleate unsaturations. While $\mathrm{ME}$ addition turned out to be quantitative for methyl oleate, ${ }^{1} \mathrm{H}$ NMR characterization showed that only $50 \%$ of thiol grafting onto methyl linoleate was achieved. The presence of polyunsaturated chains seemed to favor competitive side reactions.

Methyl oleate and linoleate before and after reaction were characterized by size exclusion chromatography (SEC) analyses (Figure 6). Before thiol-ene addition, SEC traces of both methyl oleate and linoleate were identical. Monomodal and narrow distribution was detected (polydispersity index PDI = 1.02). Methyl oleate SEC analysis after reaction showed an increase of the molecular weight value, corresponding to the mercaptoethanol addition onto double bonds, and a narrow distribution. On the contrary, SEC trace of the grafted methyl linoleate revealed a shoulder in the high molecular weight region (Figure 6). Thiol addition onto methyl linoleate yielded about $10 \%$ of various dimers.

The following observations can be finally drawn from LC-MS analyses: the methyl ester adducts contained isomers of expected thioethers (with a mercaptan grafting onto 9th or 10th position of the chain for methyl oleate and on 12th or 13th position for

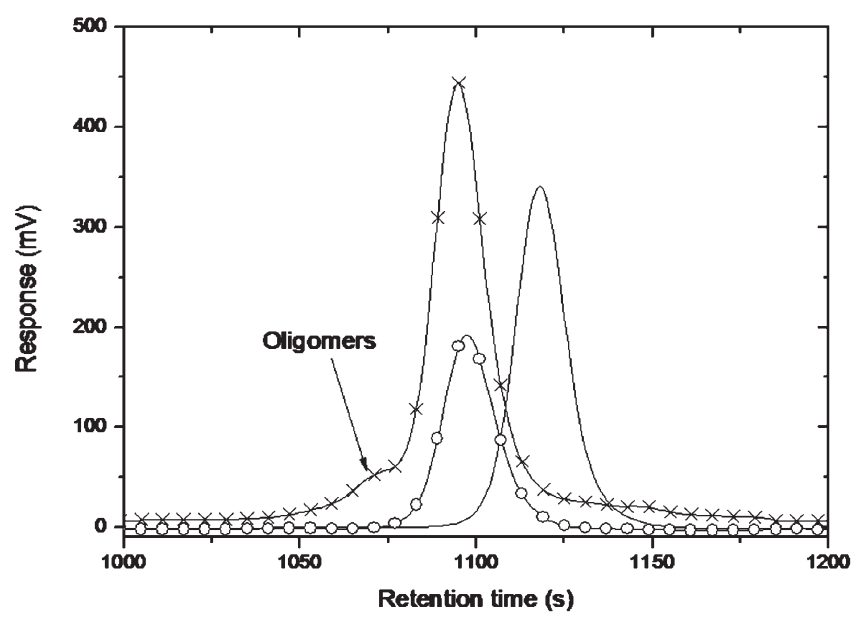

Figure 6. Size exclusion chromatography traces of methyl esters and their products after the mercaptoethanol addition: methyl oleate and linoleate (full line), functionalized methyl oleate $(O)$, and functionalized methyl linoleate $(\times)$. A thiol/double bond stoichiometric mixture of 3 / 1 was irradiated in both cases at $15 \mathrm{~W} / \mathrm{cm}^{2}$ until complete double-bond conversion.

methyl linoleate). Unmodified compounds (or cyclized one) were identified, and dimers were detected (Table 2).

On the basis of these observations, the following experimental parameters were chosen for rapeseed oil functionalization: bulk conditions, a thiol/ene ratio of $3 / 1$ and a UV intensity of $15 \mathrm{~W} / \mathrm{cm}^{2}$. Longer reaction time might be required, according to rapeseed oil average composition. In addition, double-bondconsuming side reactions may be expected.

Thiol-Ene Reaction for Polyol Synthesis from Vegetable Oils. ME addition to rapeseed oil (RO) was carried out by UV irradiation (experiment 19). The functionalized RO was subsequently purified by liquid-liquid extraction to remove ME and disulfide, as mentioned above. The acid index before and after reaction was determined to be $I_{\mathrm{a}}=2.5 \mathrm{mg} \mathrm{KOH} / \mathrm{g}$. This value was consistent with that of the supplier and showed that hydrolysis was negligible. Ideally, all the double bonds should be converted into desired alcohol.

This conversion was monitored by the disappearance of both signals at 5.40 and $1.98 \mathrm{ppm}$ assigned to $(\mathrm{CH}=\mathrm{CH})$ and $\left(=\mathrm{CH}-\mathrm{CH}_{2}\right)$, respectively, from ${ }^{1} \mathrm{H} \mathrm{NMR}$ spectrum of synthesized product (Figure 7). $5 \mathrm{~h}$ was required for obtaining a complete double-bond conversion. The chemical structure of the functionalized oil was confirmed by a multiplet signal at $2.6 \mathrm{ppm}(\mathrm{CH}-\mathrm{S})$. Noteworthy, only $65 \%$ of double bonds were actually functionalized with ME. Thus, $35 \%$ were due to the byproduct formation. End-group analysis, considering the signal of the chain end methyl protons, allowed calculating the content of linolenic chains functionalized in the $\mathrm{C} 16$ position $\left(\mathrm{SCH}-\mathrm{CH}_{2}-\mathrm{CH}_{3}, 1.0 \mathrm{ppm}\right)$. Ferreri et al. ${ }^{46}$ reported that thiyl radical could extract, to some extent, an allyl hydrogen from carbon chain, thus forming conjugated polyene. Their conclusions were based on double bond shifts (6.1 and $6.4 \mathrm{ppm})$ from ${ }^{1} \mathrm{H}$ NMR spectra. No shift was detected in the present study. Nevertheless, it was noted an evolution of vinyl protons $(\mathrm{CH}=\mathrm{CH})$ intensity during the course of the reaction, which evidenced the isomerization mechanism. The disulfide formation described above was evaluated to $0.5 \mathrm{~mol} \%$, as calculated from ${ }^{1} \mathrm{H}$ NMR spectroscopy. Disulfide concentration was lower than 

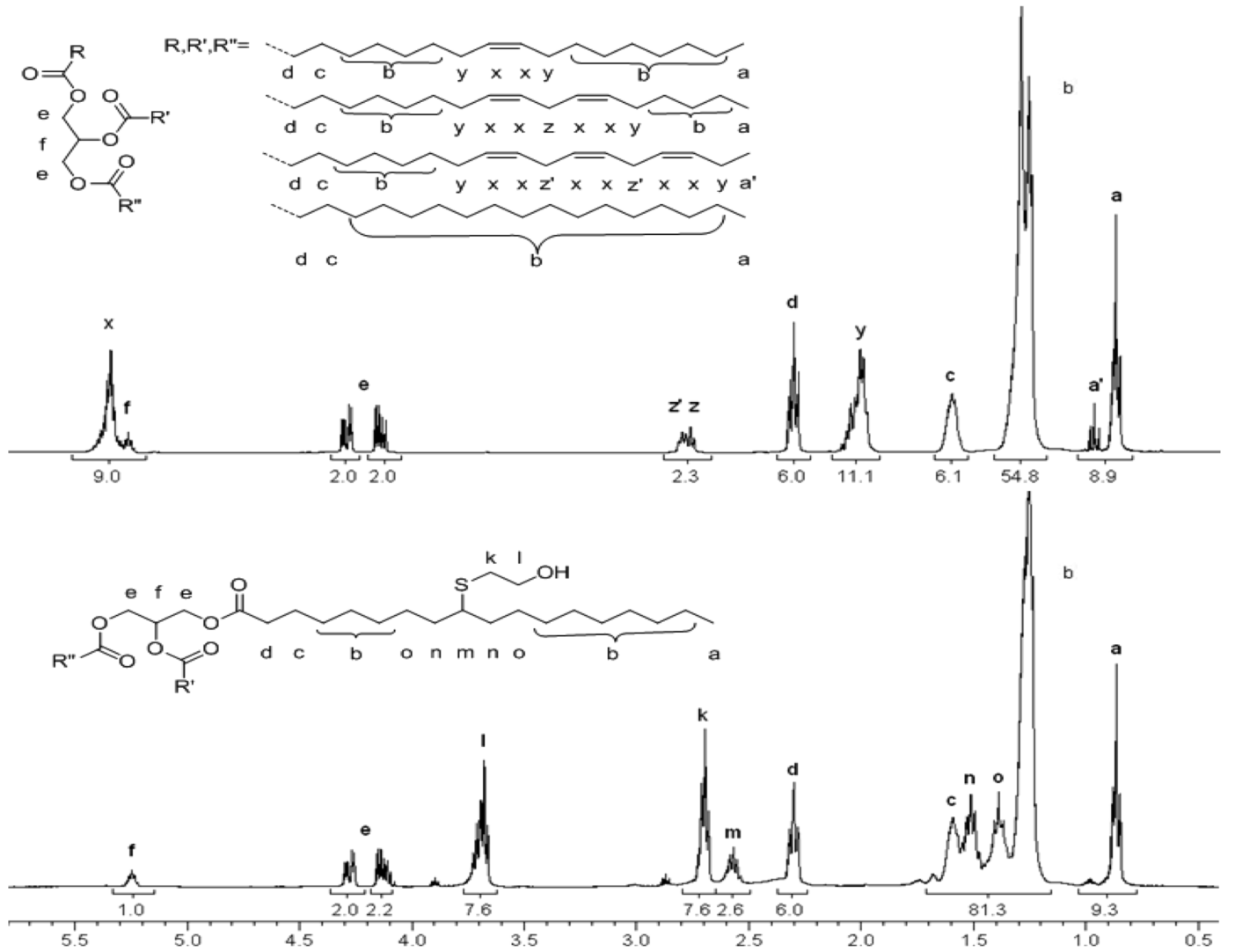

Figure 7. ${ }^{1} \mathrm{H}$ NMR spectra $\left(\mathrm{CDCl}_{3}\right)$ of rapeseed oil and its product after the thiol-ene coupling with 2-mercaptoethanol. A thiol/double bond ratio of $3 / 1$ was irradiated $5 \mathrm{~h}$ at $15 \mathrm{~W} / \mathrm{cm}^{2}$.

for oleic acid. This observation may confirm the disulfide dependence to acidity.

FT-IR analysis allowed monitoring dodecanethiol addition onto RO (experiment 20), and both isomerization ${ }^{46}$ and double-bond conversion were evidenced, as already described (experiments 16 and 18). It is worth noting that reaction rate on RO was close to the one observed on methyl linoleate. The second linoleic double bond might be less reactive because of the steric effect of additional side chain. Plotting the double-bond conversion vs time (Figure S4 from Supporting Information) indicated that reaction did not occur without UV irradiation, which confirmed the radical addition mechanism. This behavior implied a control of the reaction and allowed reaching intermediate conversion yields.

SEC chromatograms of RO before and after reaction (Figure 8) indicated an increase of molecular weight value, corresponding to $\mathrm{ME}$ addition. Futhermore, a thiol/ene ratio of 5/1 led to $11 \mathrm{~mol} \%$ of oligomer. Those oligomers most probably corresponded to dimers and trimers of grafted triglycerides.

This observation was consistent with results obtained by Bantchev et al. ${ }^{33}$ Vegetable oil oligomerization was previously studied through thermal and catalytic mechanisms. ${ }^{47}$ Oligomerization was also carried out under UV exposure; this reaction occurred through a self-oxidation mechanism ${ }^{48}$ by formation of hydroperoxides and cyclic peroxides. This first step was followed by their decomposition, yielding to radicals that allow intermolecular coupling. Blank experiment on irradiated RO without other reagent (experiment 21) presented a slightly different SEC trace from crude oil. A peak was observed in the high molecular weight region, indicating that unsaturated oil led to

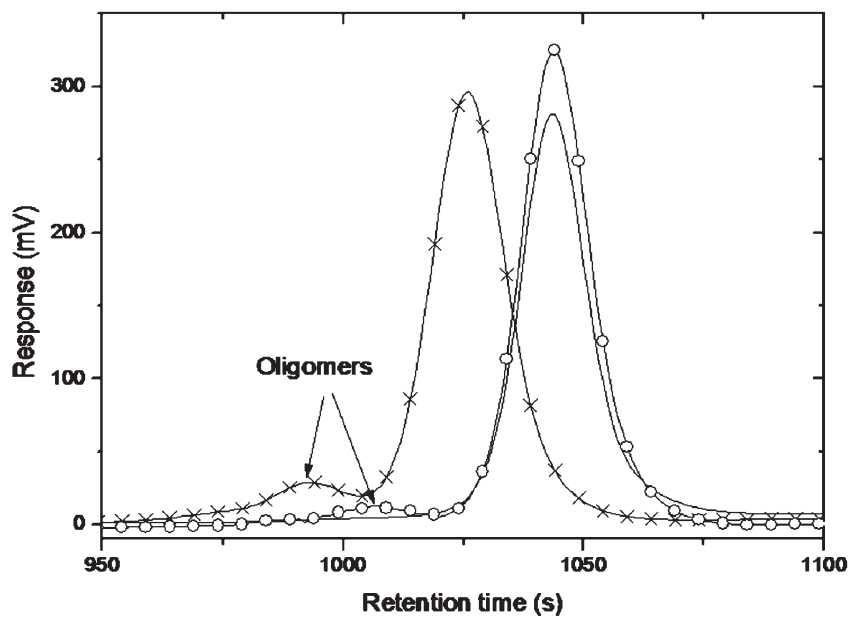

Figure 8. Size exclusion chromatography traces of rapeseed oil before functionalization (full line), blank experiment $(\mathrm{O})$, and after functionalization by 2 -mercaptoethanol addition $(\times)$. A thiol/double ratio bond of $3 / 1$ was irradiated $6 \mathrm{~h}$ at $15 \mathrm{~W} / \mathrm{cm}^{2}$.

oligomers. The question now arises whether monounsaturated triglycerides form oligomers or not. ME addition on triolein (Scheme 1c) was performed under conventional experimental conditions (experiment 22). Double bonds were consumed after only $1 \mathrm{~h}$ irradiation. The polydispersity index, given by SEC, was 1.02, indicating that the functionalized oil exhibited a narrow molecular weight distribution. This result confirmed the model observations. Polyunsaturated fatty compounds favored 
Table 3. LC-MS Data for 2-Mercaptoethanol Grafted Rapeseed Oil Obtained from $6 \mathrm{~h}$ Irradiation of a Thiol/Ene Mixture of 3/1, with an Irradiance of $15 \mathrm{~W} / \mathrm{cm}^{2 a}$

\begin{tabular}{|c|c|c|c|c|c|}
\hline triglyceride & $m / z$ & triglyceride & $m / z$ & triglyceride & $m / z$ \\
\hline $\mathrm{C} 16: 01 \mathrm{ME}$ & $1074.1-\mathrm{H}_{2} \mathrm{O}$ & $\mathrm{C} 18: 11 \mathrm{ME}$ & 1249.2 & $\mathrm{C} 18: 02 \mathrm{ME}$ & $1325.3-\mathrm{H}_{2} \mathrm{O}$ \\
\hline $\mathrm{C} 18: 0 \mathrm{1ME}$ & & C20:1 1ME & & $\mathrm{C} 18: 12 \mathrm{ME}$ & \\
\hline $\mathrm{C} 18: 01 \mathrm{ME}$ & & $\mathrm{C} 20: 02 \mathrm{ME}$ & & $\mathrm{C} 18: 12 \mathrm{ME}$ & \\
\hline $\mathrm{C} 18: 01 \mathrm{ME}$ & 1120.1 & C18:1 1ME & 1269.2 & $\mathrm{C} 18: 02 \mathrm{ME}$ & 1348.1 \\
\hline $\mathrm{C} 18: 0 \mathrm{1ME}$ & & $\mathrm{C} 18: 02 \mathrm{ME}$ & & $\mathrm{C} 18: 02 \mathrm{ME}$ & \\
\hline $\mathrm{C} 18: 0 \mathrm{1ME}$ & & $\mathrm{C} 18: 12 \mathrm{ME}$ & & $\mathrm{C} 18: 02 \mathrm{ME}$ & \\
\hline $\mathrm{C} 18: 1 \mathrm{ME}$ & 1193.2 & $\mathrm{C} 18: 01 \mathrm{ME}$ & 1272.1 & $\mathrm{C} 18: 12 \mathrm{ME}$ & 1373.2 \\
\hline $\mathrm{C} 18: 1 \mathrm{ME}$ & & $\mathrm{C} 18: 02 \mathrm{ME}$ & & $\mathrm{C} 18: 12 \mathrm{ME}$ & \\
\hline $\mathrm{C} 18: 02 \mathrm{ME}$ & & $\mathrm{C} 18: 02 \mathrm{ME}$ & & C20:0 2ME & \\
\hline $\mathrm{C} 18: 0 \mathrm{MME}$ & 1221.2 & $\mathrm{C} 18: 1 \mathrm{ME}$ & 1297.2 & C18:0 3ME & 1449.3 \\
\hline $\mathrm{C} 18: 1 \mathrm{ME}$ & & $\mathrm{C} 18: 02 \mathrm{ME}$ & & $\mathrm{C} 18: 12 \mathrm{ME}$ & \\
\hline C20:1 1ME & & $\mathrm{C} 20: 02 \mathrm{ME}$ & & C20:1 2ME & \\
\hline
\end{tabular}

${ }^{a}$ Triglycerides description follows: number of carbon atoms per fatty acid is given by the first digit (C18), the second one is the number of unsaturated bonds after reaction, or intramolecular bonds (C18:1). The digit before ME indicates the number of mercaptoethanol molecules grafted on fatty acid chain $(2 \mathrm{ME})$. These descriptions are one possible arrangement of triglyceride molecule. Indeed, a given $\mathrm{m} / z$ could correspond to several molecules; for example, $m / z=1120.1 \mathrm{~g} / \mathrm{mol}$ could be

$\begin{array}{llll}\mathrm{C} 18: 02 \mathrm{ME} & \mathrm{C} 18: 03 \mathrm{ME} & \mathrm{C} 18: 0 & \mathrm{C} 18: 01 \mathrm{ME} \\ \mathrm{C} 18: 01 \mathrm{ME} & \mathrm{C} 18: 0 & \mathrm{C} 18: 02 \mathrm{ME} & \mathrm{C} 18: 0 \\ \mathrm{C} 18: 0 & \mathrm{C} 18: 0 & \mathrm{C} 18: 01 \mathrm{ME} & \mathrm{C} 18: 02 \mathrm{ME}\end{array}$

Table 4. Thermal Characterization of Polyurethanes Formulated with a $\mathrm{OH} / \mathrm{NCO}$ Ratio of $1.00 / 1.05$, Cured at $65^{\circ} \mathrm{C}$ for $24 \mathrm{~h}$

\begin{tabular}{|c|c|c|c|}
\hline polyurethane $^{a}$ & $T_{\mathrm{g}}\left({ }^{\circ} \mathrm{C}\right)$ & $\begin{array}{l}\text { mass loss at } \\
200{ }^{\circ} \mathrm{C}(\%)\end{array}$ & $\begin{array}{l}\text { residual mass at } \\
500{ }^{\circ} \mathrm{C}(\%)\end{array}$ \\
\hline functionalized RO + MDI & 25 & 0.2 & 4.3 \\
\hline functionalized RO + HDI & -23 & 0.8 & 0.8 \\
\hline Desmophen $1150+$ MDI & 8 & 0.9 & 2.9 \\
\hline Desmophen 1150 + HDI & -20 & 1.4 & 1.5 \\
\hline \multicolumn{4}{|c|}{$\begin{array}{l}{ }^{a} \text { RO: rapeseed oil; MDI: methylene diphenyl-4,4'-diisocyanate; HDI } \\
\text { hexamethylene diisocyanate. }\end{array}$} \\
\hline
\end{tabular}

oligomerization and decreased reaction rate. Therefore, vegetable oil choice is crucial as far as intermolecular coupling is concerned.

LC-MS analysis of functionalized oil (Table 3) showed triglycerides bearing 2-7 ME molecules, which meant that grafting efficiently occurred. The ratios of each species cannot be evaluated from this technique. Besides, it was not possible to know if a difference of $2 \mathrm{~m} / z$ corresponded to unreacted unsaturation, intramolecular linkage, or cyclization.

SEC analysis allowed detecting intermolecular head-to-head coupling of the carbon-centered radicals, which significantly increased molecular weight distribution; therefore, intramolecular cross-linking was not detectable. GC-MS analysis realized on functionalized methyl esters of RO could give information on side reaction, such as termination, especially on the possibility to create intramolecular bonds. Even if no difference could be made between inter- and intramolecular recombination, it would give an estimation of all possible recombinations between two $\mathrm{C}^{\bullet}$ radicals. Investigation of quantitative analyses of cross-linking is in progress.

Elastomeric polyurethanes have been synthesized by reaction of hydroxy-functionalized RO with both methylene diphenyl-4, $4^{\prime}$ - diisocyanate (MDI) and hexamethylene diisocyanate (HDI). After the assessment of the polyols hydroxyl index $\left(I_{\mathrm{OH}}=165\right.$ $\mathrm{mg} \mathrm{KOH} / \mathrm{g}$ for Desmophen 1150 and $223 \mathrm{mg} \mathrm{KOH} / \mathrm{g}$ for functionalized RO), suitable amounts of polyol and diisocyanate were mixed, and the samples were cured at $65{ }^{\circ} \mathrm{C}$ for $24 \mathrm{~h}$. The thermal properties of the oleochemical-based polyurethanes were compared to the one of polyurethane based on a commercial polyether polyester polyol, named Desmophen 1150. Both differential scanning calorimetry (DSC) and thermogravimetric (TG) results exhibited similar thermal behavior when the same diisocyanate was used (Table 4).

As expected, the use of $\mathrm{HDI}$ instead of MDI allowed reducing the polymer $T_{\mathrm{g}}$ value. Polyurethanes based on functionalized RO exhibited a wide range of $T_{\mathrm{g}}$ values. The oleochemical polyol was found to be suitable for polyurethane synthesis. Mechanical characterizations are under investigation, and the results will be given in a forthcoming article.

\section{CONCLUSIONS}

The efficient thiol addition onto vegetable oil, leading to biobased polyol, was demonstrated. Experimental parameters of mercaptoethanol addition onto oleic acid were investigated and optimized. The most important feature probably arose from the number of double bonds per chain in vegetable oil, which strongly influenced the thiol grafting yield. Experimental conditions were chosen to reduce reaction time and byproducts, and yet several byproducts were identified. Indeed, disulfide formation and intermolecular recombination occurred, and in the case of oleic acid functionalization, transesterification was also detected. Despite these side reactions, byproducts were found to exhibit alcohol functions. Interestingly, the photoreaction can therefore be performed under mild conditions, requiring neither solvent nor photoinitiator, and the crude product could be purified by an easy procedure. Even if the reaction does not 
match "click chemistry" requirements, it can be classified as an efficient functionalization procedure. ${ }^{49}$ Thus, the formed mixture has been used for polyurethane synthesis. This one-step route to produce fatty polyols represents a significant advance compared to the traditional epoxidation approach (that occurs in two steps) and further evidence of the synthetic usefulness of thiol addition in materials chemistry. Indeed, the synthetic method can readily undergo incorporation of different reactive functions onto vegetable oils and their derivatives, thus leading to functional precursors suitable for polymer synthesis.

\section{ASSOCIATED CONTENT}

S Supporting Information. Table S1 and Figures S1-S4. This material is available free of charge via the Internet at http:// pubs.acs.org.

\section{AUTHOR INFORMATION}

\section{Corresponding Author}

*E-mail remi.auvergne@enscm.fr, Tel +33467144305, Fax +33467147220 .

\section{ACKNOWLEDGMENT}

This work was supported by ANR project MatetPro, Resipoly Chrysor, and SEG Dielectriques companies. We thank Croda and Novance companies for giving oleochemical products. We are also grateful to Guillaume Cazals for mass analysis.

\section{REFERENCES}

(1) Gunstone, F. D. Eur. J. Lipid Sci. Technol. 2001, 103, 307-314.

(2) Corma, A.; Iborra, S.; Velty, A. Chem. Rev. 2007, 107, 2411-2502.

(3) Zanetti-Ramos, B. G.; Lemos-Senna, E.; Soldi, V.; Borsali, R.; Cloutet, E.; Cramail, H. Polymer 2006, 47, 8080-8087.

(4) Yeganeh, H.; Hojati-Talemi, P. Polym. Degrad. Stab. 2007, 92, 480-489.

(5) Guo, A.; Javni, I.; Petrovic, Z. J. Appl. Polym. Sci. 2000, 77, 467-473.

(6) Harry-O'kuru, R. E.; Holser, R. A.; Abbott, T. P.; Weisleder, D. Ind. Crop. Prod. 2002, 15, 51-58.

(7) Hwang, H.-S.; Erhan, S. J. Am. Oil Chem. Soc. 2001, $78,1179-1184$

(8) Dahlke, B.; Hellbardt, S.; Paetow, M.; Zech, W. J. Am. Oil Chem. Soc. 1995, 72, 349-353.

(9) Sharma, V.; Kundu, P. P. Prog. Polym. Sci. 2008, 33, 1199-1215.

(10) Petrovic, Z. S.; Zhang, W.; Javni, I. Biomarcomolecules 2005, 6, 713-719.

(11) Campos, L. M.; Killops, K. L.; Sakai, R.; Paulusse, J. M. J.; Damiron, D.; Drockenmuller, E.; Messmore, B. W.; Hawker, C. J. Macromolecules 2008, 41, 7063-7070.

(12) Boutevin, G.; Ameduri, B.; Boutevin, B.; Joubert, J. P. J. Appl. Polym. Sci. 2000, 75, 1655-1666.

(13) Justynska, J.; Hordyjewicz, Z.; Schlaad, H. Polymer 2005, 46, 12057-12064.

(14) Lowe, A. B. Polym. Chem. 2010, 1, 17-36.

(15) Schwab, A.; Gast, L.; Cowan, J. J. Am. Oil Chem. Soc. 1968, 45, 461-464.

(16) Lluch, C.; Ronda, J. C.; Galià, M.; Lligadas, G.; Càdiz, V. Biomacromolecules 2010, 11, 1646-1653.

(17) Turunc, O.; Meier, M. A. R. Green Chem. 2011, 13 (2), 314-320.

(18) Samuelsson, J.; Jonsson, M.; Brinck, T.; Johansson, M. J. Polym. Sci., Part A: Polym. Chem. 2004, 42, 6346-6352.

(19) Black, M.; Rawlins, J. W. Eur. Polym. J. 2009, 45, 1433-1441.

(20) Bexell, U.; Olsson, M.; Johansson, M.; Samuelsson, J.; Sundell,

P.-E. Surf. Coat. Technol. 2003, 166, 141-152.
(21) Türünç, O.; Meier, M. A. R. Macromol. Rapid Commun. 2010, $31,1822-1826$.

(22) Kolb, H. C.; Finn, M. G.; Sharpless, K. B. Angew. Chem., Int. Ed. 2001, 40, 2004-2021.

(23) Hoyle, C. E.; Lowe, A. B.; Bowman, C. N. Chem. Soc. Rev. 2010, 39, 1355-1387.

(24) Kade, M. J.; Burke, D. J.; Hawker, C. J. J. Polym. Sci., Part A: Polym. Chem. 2010, 48, 743-750.

(25) Carlson, D.; Knight, A. R. Can. J. Chem. 1973, 51, 1410-1415.

(26) David, R. L. A.; Kornfield, J. A. Macromolecules 2008, 41, 1151-1161.

(27) Boutevin, B.; Hervaud, Y.; Moulédous, G. Polym. Bull. 1998, $41,145-151$.

(28) Gress, A.; Völkel, A.; Schlaad, H. Macromolecules 2007, 40, $7928-7933$.

(29) Schapman, F.; Couvercelle, J. P.; Bunel, C. Polymer 1998, 39, 4955-4962.

(30) Lotti, L.; Coiai, S.; Ciardelli, F.; Galimberti, M.; Passaglia, E. Macromol. Chem. Phys. 2009, 210, 1471-1483.

(31) Passaglia, E.; Donati, F. Polymer 2007, 48, 35-42.

(32) Koo, S. P. S.; Stamenovic, M. M.; Prasath, R. A.; Inglis, A. J.; Du Prez, F. E.; Barner-Kowollik, C.; Van Camp, W.; Junkers, T. J. Polym. Sci., Part A: Polym. Chem. 2010, 48, 1699-1713.

(33) Bantchev, G. B.; Kenar, J. A.; Biresaw, G.; Han, M. G. J. Agric. Food Chem. 2009, 57, 1282-1290.

(34) Samadi, A.; Andreu, I.; Ferreri, C.; Dellonte, S.; Chatgilialoglu, C. J. Am. Oil Chem. Soc. 2004, 81, 753-758.

(35) Danehy, J. P.; Oester, M. Y. J. Org. Chem. 1967, 32, 1491-1495.

(36) Roper, T. M.; Guymon, C. A.; Jönsson, E. S.; Hoyle, C. E. J. Polym. Sci., Part A: Polym. Chem. 2004, 42, 6283-6298.

(37) Claudino, M.; Johansson, M.; Jonsson, M. Eur. Polym. J. 2010, $46,2321-2332$.

(38) Walling, C.; Helmreich, W. J. Am. Chem. Soc. 1959, 81, 1144-1148.

(39) Coates, J. In Encyclopedia of Analytical Chemistry; Meyers, R. A., Ed.; John Wiley \& Sons Ltd.: Chichester, 2000; pp 10815-10837.

(40) Karol, T. J.; Sung, R. L. Reaction product of beta-mercaptoethanol and coconut oil as diesel fuel antiwear additive. U.S. Patent 06,710,650, 1986.

(41) Christie, W. W.; Dobson, G. Eur. J. Lipid Sci. Technol. 2000, 102, 515-520.

(42) Destaillats, F.; Angers, P. Eur. J. Lipid Sci. Technol. 2005, 107, $767-772$.

(43) Hoyle, C., E.; Lee, T. Y.; Roper, T. J. Polym. Sci., Part A: Polym. Chem. 2004, 42, 5301-5338.

(44) Griesbaum, K. Angew. Chem., Int. Ed. Engl. 1970, 9, 273-287.

(45) Muizebelt, W. J.; Nielen, M. W. F. J. Mass Spectrom. 1996, $31,545-554$.

(46) Ferreri, C.; Costantino, C.; Perrotta, L.; Landi, L.; Mulazzani, Q. G.; Chatgilialoglu, C. J. Am. Chem. Soc. 2001, 123, 4459-4468.

(47) Lopes, R. V. V.; Loureiro, N. P. D.; Zamian, J. R.; Fonseca, P. S.; Macedo, J. L.; dos Santos, M. L.; Sales, M. J. A. Macromol. Symp. 2009, 286, 89-94.

(48) Lazzari, M.; Chiantore, O. Polym. Degrad. Stab. 1999, 65, 303-313.

(49) Barner-Kowollik, C.; Du Prez, F. E.; Espeel, P.; Hawker, C. J.; Junkers, T.; Schlaad, H.; Van Camp, W. Angew. Chem., Int. Ed. 2011, $50,60-62$. 